УДК 537.622

\title{
Numerical Simulation of Magnetic Microstructure in Nanocrystalline Thin Films with the Random Anisotropy
}

\author{
Boris A. Belyaev \\ Andrey V. Izotov \\ Platon N. Solovev* \\ Kirensky Institute of Physics SB RAS \\ Akademgorodok, 50/38, Krasnoyarsk, 660036 \\ Institute of Engineering Physics and Radio Electronics \\ Siberian Federal University \\ Svobodny, 79, Krasnoyarsk, 660041
}

Russia

Received 20.08.2016, received in revised form 10.10.2016, accepted 14.11.2016

The magnetic structure of thin nanocrystalline films with a random distribution of magnetization easy axes was studied by means of micromagnetic modeling. The dependences of the correlation function parameters of the non-uniform magnetization on the value of the external in-plane magnetic field were investigated in the wide range (6-1000 $\mathrm{nm}$ ) of particles sizes. An analysis of the obtained dependences revealed a significant difference between longitudinal (along the field) and transversal (perpendicular to the field) correlation radii of a stochastic magnetic structure. The blocking effect of a fine magnetic structure-a magnetization ripple-was observed during magnetization reversal of the films.

Keywords: micromagnetic simulation, thin magnetic film, nanocrystallites, random anisotropy model. DOI: 10.17516/1997-1397-2017-10-1-132-135.

\section{Introduction}

Thin nanocrystalline films belong to the class of magnetically soft nanostructured materials, which properties are studied widely because of great prospects of their practical applications $[1,2]$. Among various characterization techniques of such materials, the correlation magnetometry method is now being actively developed [3,4]. This method is based on the interpretation of microscopic properties of nanostructured ferromagnets from an analysis of the integral magnetization curve behavior. Using the law of approach of the magnetization to saturation, such important characteristics of a non-uniform magnetic microstructure as a normalized dispersion $d_{m}$ and a correlation radius $R_{m}$ of transversal components of the equilibrium magnetization are obtained $[3,4]$. The existence of a direct relation between correlation and microscopic parameters in nanostructured materials gives a principal opportunity to evaluate microstructural and magnetic parameters of the samples. The determination of this relation is a very complex and important task, to solve which experimental and theoretical studies are needed.

The aim of this work is to study by micromagnetic modeling the correlation between the magnetic microstructure, local ordering of magnetic moments, microstructural and magnetic properties of thin films composed of particles with randomly oriented easy axes of magnetization.

*platon.solovev@gmail.com

(c) Siberian Federal University. All rights reserved 


\section{Modeling details}

We used our micromagnetic modeling software $[5,6]$ to study the magnetic microstructure of thin nanocrystalline films. The investigated films were monolayers of close-packed nanoparticles with a random distribution of anisotropy axes, where the number of the particles was $2048 \times 2048 \times 1$. The size of the nanoparticles varied from 6 to $1000 \mathrm{~nm}$. We used two-dimensional infinite periodic boundary conditions for the exchange and magnetostatic interactions to eliminate edge effects originating from a non-uniformity of an internal magnetic field in samples of finite sizes [7]. We used the following magnetic parameters in the calculations: the saturation magnetization $M_{s}=955 \mathrm{G}(1.2 \mathrm{~T})$, the exchange constant $A=1 \times 10^{6} \mathrm{erg} / \mathrm{cm}\left(1 \times 10^{11} \mathrm{~J} / \mathrm{m}\right)$, and the uniaxial anisotropy field $H_{k}=2 K_{1} / M_{s}=171.7$ Oe $\left(K_{1}=8200 \mathrm{~J} / \mathrm{m}^{3}\right)$. In all calculations, we used the same random distribution of anisotropy axes. The overall magnetic anisotropy of the films was not taken into account to ease an analysis of results. An external in-plane magnetic field $H$ was applied along the $O x$ axis.

\section{Results and discussion}

Fig. 1 shows (in a logarithmic scale) the dependences of the correlation function parameters of the magnetization transversal components $M_{y}$ on the external field value $H$ and the particles size $D$ in the thin nanocrystalline films. A flat area (outlined schematically by dashed lines) is clearly seen on the $d_{m}(H, D)$ surface plotted in Fig. 1a. The power dependence $d_{m} \sim H^{-0.724 \pm 0.026}$ in this area agrees well with the Hoffmann's theory [8], according to which $d_{m} \sim H^{-3 / 4}$. For the region of large values of the magnetic field, the power dependence $d_{m}$ tends to $H^{-2}$, whereas for the small values of $H$ this dependence tends to a constant value.
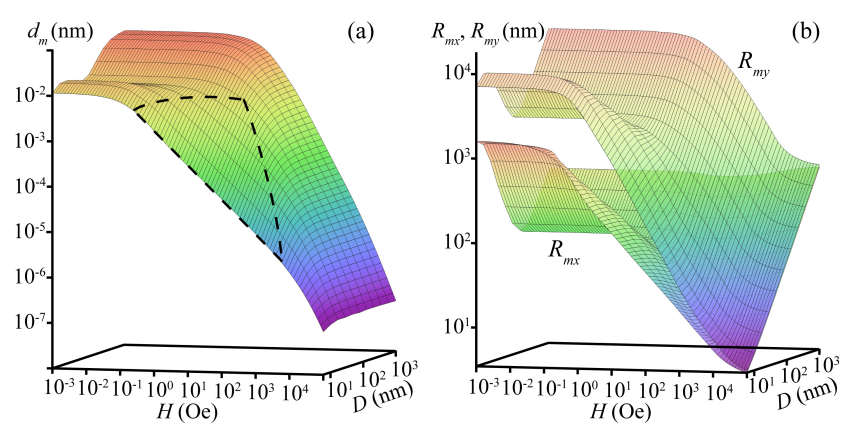

Fig. 1. The dependence of the normalized dispersion $d_{m}$ of the magnetization transversal components (a) and magnetization correlation radii $R_{m x}$ (along the field) and $R_{m y}$ (perpendicular to the field) (b) on the external field $H$ and particles size $D$ in thin nanocrystalline films. A logarithmic scale is used for all axes

Fig. 1b demonstrates (also in a logarithmic scale) surfaces of the longitudinal (along the field) $R_{m x}(H, D)$ and the transversal (perpendicular to the field) $R_{m y}(H, D)$ correlation radii of the stochastic magnetic structure. These results show that the $R_{m x}(H, D)$ and $R_{m y}(H, D)$ qualitatively agree with each other but depend differently on the external field $H$. Therefore, it is necessary to take into account this substantial difference between $R_{m x}$ and $R_{m y}$ when calculating sizes of the so-called "stochastic magnetic domains" studied in Ref. [4].

Fig. 2 shows the variations in a micromagnetic structure during magnetization reversal of 
a thin nanocrystalline film with $D=12 \mathrm{~nm}$. These pictures are very like the images of a magnetization ripple obtained on real films $[9,10]$. With the external field decreasing, starting from about $10 \mathrm{kOe}$, a fine magnetic structure - the magnetization ripple - is formed in the sample. Our calculations show that the wavelength $\lambda_{L}$ of the longitudinal magnetization ripple changes as $\lambda_{L} \sim H^{-0.43 \pm 0.12}$ for $H$ values up to $\approx 0.1$ Oe. The power dependence $\lambda_{L}(H)$ is also in good agreement with the theory of magnetization ripple [8], according to which $\lambda_{L} \sim H^{-1 / 2}$.

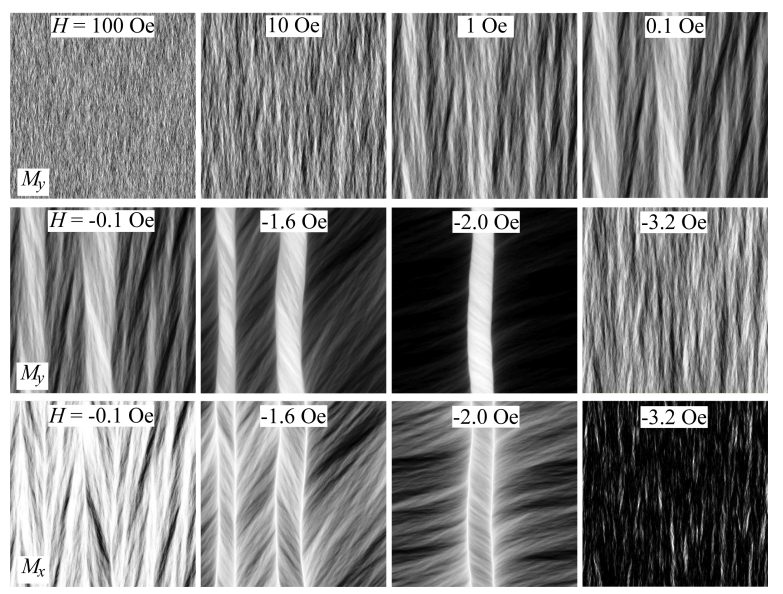

Fig. 2. Modeled distributions of the transversal $M_{y}$ and the longitudinal $M_{x}$ components of the equilibrium magnetization across the film surface with the size of the particle $D=12 \mathrm{~nm}$ for the various values of the external field $H$

For $H \approx 0.1 \mathrm{Oe}$, the wavelength $\lambda_{L}$ becomes constant. Here, a domain structure is forming, which stray fields block the magnetic structure, as shown in Ref. [8,9]. For $H \approx-1.6$ Oe, a pronounced stripe domain structure is formed, with the magnetization ripple within each domain. With further decreasing of the external field $H$, domain wall movement releases the blocking and for $H \approx-3.2$ Oe the magnetization is fully reversed.

\section{Conclusion}

In summary, the results of the present study proves that it is efficient to use a numerical micromagnetic modelling for the investigation of the magnetization reversal processes and the magnetic structure in nanocrystalline films.

This work was supported by Russian Science Foundation (project no. 16-12-10140).

\section{References}

[1] J.Petzold, Advantages of softmagnetic nanocrystalline materials for modern electronic applications, J. Magn. Magn. Mater., 242-245(2002), 84.

[2] I.Fergena, K.Seemann, A.v.d.Weth, A.Schuppen, Soft ferromagnetic thin films for high frequency applications, J. Magn. Magn. Mater., 242-245(2002), 146. 
[3] V.A.Ignatchenko, R.S.Iskhakov, Stochastic properties of non-uniformities of amorphous magnetics, Magnetic properties of crystalline and amorphous media, Novosibirsk, Nauka, 1989, 128-142 (in Russian).

[4] R.S.Iskhakov, V.A.Ignatchenko, S.V.Komogortsev, A.D.Balaev, Study of magnetic correlations in nanostructured ferromagnets by correlation magnetometry, JETP Letters, $\mathbf{7 8}(2003)$, 646 .

[5] B.A.Belyaev, A.V.Izotov, A.A.Leksikov, Micromagnetic calculation of the equilibrium distribution of magnetic moments in thin films, Phys. Sol. State, 52(2010), 1664.

[6] A.V.Izotov, B.A.Belyaev, A method for computing the microwave absorption spectrum in a discrete model of a ferromagnetic, Russ. Phys. J., 53(2011), 900.

[7] K.M.Lebecki, M.J.Donahue, M.W.Gutowski, Periodic boundary conditions for demagnetization interactions in micromagnetic simulations, J. Phys. D: Appl. Phys., 41(2008), 175005.

[8] H.Hoffmann, Theory of magnetization ripple, IEEE Trans. Magn. Mag-4(1968), 32.

[9] V.I.Petrov, G.V.Spivak, O.P.Pavluchenko, Electronic microscopy of thin films magnetic structure, UFN, 106(1972), 229 (in Russian).

[10] J.McCord, R.Schafer, R.Mattheis, K.-U.Barholz, Kerr observations of asymmetric magnetization reversal processes in CoFe/IrMn bilayer systems, J. Appl. Phys., 93(2003), 5491.

\title{
Численное моделирование магнитной микроструктуры нанокристаллических тонких пленок со случайной анизотропией
}

\author{
Борис А. Беляев \\ Андрей В. Изотов \\ Платон Н. Соловьев \\ Институт инженерной физики и радиоэлектроники \\ Сибирский федеральный университет \\ Свободный, 79, Красноярск, 660041 \\ Институт физики им. Л. В. Киренского СО РАН \\ Академгородок, 50/38, Красноярск, 660036
}

Россия

\begin{abstract}
Методом микромагнитного моделирования проведены исследования магнитной структуры тонких нанокристаллических пленок со случайным распределением осей легкого намагничивания. $B$ широком диапазоне размеров частич, 6-1000 нм исследованы зависимости параметров корреляционной функции неоднородной намагниченности от величины внешнего планарного магнитного поля. Анализ полученных зависимостей показал существенное различие корреляиионных радиусов стохастической магнитной структуры вдоль и поперек направления приложенного поля. При перемагничивании тонких пленок наблюдался эффект блокировки тонкой магнитной структурь «ряби намагниченности».
\end{abstract}

Ключевые слова: микромагнитное моделирование, тонкая магнитная пленка, нанокристаллиты, модель случайной анизотропии. 